\title{
Role of immunoreactive patterns of lymph nodes in neck dissection cases of oral squamous cell carcinoma: a clinical and histopathological study
}

\author{
Harshada C. Bhatlawande ${ }^{1}$, Alka D. Kale ${ }^{1}$, Karishma M. Desai ${ }^{1}$, Seema Hallikerimath ${ }^{1}$, Chetan Belaldavar ${ }^{1}$, \\ Deepa Mane ${ }^{1}$, Punnya V. Angadi ${ }^{1}$, Manjula M. ${ }^{1}$, Sidramesh Muttagi ${ }^{2}$ \\ Departments of ${ }^{\prime}$ Oral Pathology and Microbiology and ${ }^{2}$ Oral and Maxillofacial Surgery, KLE Academy of Higher Education and \\ Research (KLE University), KLE VK Institute of Dental Sciences and Hospital, Belagavi, India
}

\begin{abstract}
J Korean Assoc Oral Maxillofac Surg 2019;45:267-275)
Objectives: Metastasis in oral squamous cell carcinoma (OSCC) can occur in a variety of ways, and draining lymphatics and lymph nodes serve as a common route. Prior to metastasis, lymph nodes elicit an immune response to either wall off or create a favorable environment for homing of tumor cells. This immune response to tumor stimuli is visualized by recognizing various immunoreactive patterns exhibited by the lymph node. The present study aims to evaluate the role of immuno-morphologic patterns of the lymph node in neck dissection for cases of OSCC.

Materials and Methods: Our retrospective study included 50 neck dissection cases of OSCC and a total of 1,078 lymph nodes. The grades of primary tumors with eight different immunoreactive patterns were compared. Vascularity and metastasis in lymph nodes were also evaluated.

Results: The lymphocyte predominant pattern was the most common immunoreactive pattern found in 396 of 1,078 lymph nodes. Patterns of lymphocyte predominant $(P=0.0005)$, sinus histiocytosis $(P=0.0500)$, paracortical hyperplasia $(P=0.0001)$, cortical hyperplasia $(P=0.0001)$, and increased vascularity $(P=0.0190)$ were significantly associated with tumor grade.

Conclusion: The present study adds to the understanding of lymph node immunoreactivity patterns and their correlation with tumor grade. We recommend further study of lymph node patterns for all sentinel lymph node biopsies and routine neck dissections for OSCCs.
\end{abstract}

Key words: Lymph node, Lymphatic metastasis, Squamous cell carcinoma, Neck dissection, Germinal center

[paper submitted 2018. 9. 17 / accepted 2018. 10. 30]

\section{Introduction}

Oral squamous cell carcinoma (OSCC) is associated with metastases to lymph nodes (LNs) through lymphatic draining of various regions of the oral cavity ${ }^{1}$. Despite several attempts at prevention, the incidence of OSCC has been increasing. The increase in incidence is predominantly attributed to occult metastasis to LNs. A thorough understanding of LN metastasis and its associated patterns is crucial for predicting

\footnotetext{
Harshada C. Bhatlawande

Department of Oral Pathology and Microbiology, KLE Academy of Higher Education and Research (KLE University), KLE VK Institute of Dental Sciences and Hospital, JN Medical College Campus, Nehru Nagar, Belagavi 590010, India

TEL: +91-9970385527 FAX: +0831-2470640

E-mail: harshadacb9@gmail.com

ORCID: https://orcid.org/0000-0002-1509-3209

(c) This is an open-access article distributed under the terms of the Creative Commons Attribution Non-Commercial License (http://creativecommons.org/ licenses/by-nc/4.0/), which permits unrestricted non-commercial use, distribution, and reproduction in any medium, provided the original work is properly cited. Copyright (C) 2019 The Korean Association of Oral and Maxillofacial Surgeons. All rights reserved.
}

the survival and prognosis of patients with head and neck tumors $^{2,3}$.

Immuno-morphologic analysis of harvested LNs from neck dissections is an important tool for detection and diagnosis of various types of OSCCs. LNs demonstrate a typical immune response in their reticular meshwork when an antigen is presented by antigen presenting cells and antibodies are secreted by plasma cells. This meshwork guides, supports, and fosters communication between lymphocytes and antigen presenting cells. Histologic evaluation of these morphologic and cytologic changes in LNs represents biological behavior and may help to determine disease prognosis ${ }^{4}$. Although immunemorphologic features or patterns indicate types of pathology and are well documented, the host immune mechanism is still not fully understood. This study essentially focuses on morphologic and cytologic changes in LNs by identifying, assessing, and correlating different patterns with clinical and histologic features of neck dissection cases. 


\section{Materials and Methods}

The present retrospective study includes 50 cases of formalin fixed and paraffin embedded tissues of OSCC and corresponding LNs from neck dissections. Tissue blocks were retrieved from archives of the Department of Oral Pathology and Microbiology, KLE VK Institute of Dental Sciences (Belagavi, India) from October 2015 to September 2017. Tissue sections of $4 \mu \mathrm{m}$ thickness of all levels of LNs were obtained for a total of 1,078 LNs. Tissue sections were stained with $\mathrm{H} \& \mathrm{E}$ and evaluated histopathologically.

Parameters and classification systems follow:

1) Clinical parameters: Demographic data for age and sex as obtained from departmental case records were tabulated.

2) OSCC:

(1) The grades of primary tumors were classified according to WHO Criteria into well differentiated (WD), moderately differentiated (MD), and poorly differentiated squamous cell carcinoma (PDSCC).

(2) Histopathologic features of tumor were included as follows, per Broder's and Byrne's classification: tumor grade, invasive front, neural invasion, and vascular invasion.

3) LNs: Evaluation of LNs and comparison with clinical and histopathological parameters in neck dissection cases of OSCC was obtained by consensus of three trained observers with similar experience in histopathology.

Table 1. Comparison of tumor grades by age groups

\begin{tabular}{lcccc}
\hline Age group & WDSCC & MDSCC & PDSCC & Total \\
\hline $30-39 \mathrm{yr}$ & $6(54.6)$ & $3(27.3)$ & $2(18.2)$ & $11(22.0)$ \\
$40-49 \mathrm{yr}$ & $8(72.7)$ & $2(18.2)$ & $1(9.1)$ & $11(22.0)$ \\
$50-59 \mathrm{yr}$ & $9(56.3)$ & $5(31.3)$ & $2(12.5)$ & $16(32.0)$ \\
$\geq 60 \mathrm{yr}$ & $6(50.0)$ & $4(33.3)$ & $7(16.7)$ & $12(24.0)$ \\
Total & $29(58.0)$ & $14(28.0)$ & $52.14 \pm 17.66$ & $50(100)$ \\
Mean age (yr) & $49.48 \pm 12.82$ & $49.57 \pm 10.66$ & & $49.88 \pm 12.77$ \\
Chi-square=1.5516, $P=0.9560$ & & & \\
\hline
\end{tabular}

(WDSCC: well differentiated squamous cell carcinoma, MDSCC: moderately differentiated squamous cell carcinoma, PDSCC: poorly differentiated squamous cell carcinoma)

Values are presented as number $(\%)$ or mean \pm standard deviation.

Harshada C. Bhatlawande et al: Role of immunoreactive patterns of lymph nodes in neck dissection cases of oral squamous cell carcinoma: a clinical and histopathological study. $J$ Korean Assoc Oral Maxillofac Surg 2019

Table 2. Comparison of tumor grades by sex

\begin{tabular}{lrrrr}
\hline Sex & WDSCC & MDSCC & PDSCC & Total \\
\hline Male & $20(50.0)$ & $13(32.5)$ & $7(17.5)$ & $40(80.0)$ \\
Female & $9(90.0)$ & $1(10.0)$ & $0(0.0)$ & $10(20.0)$ \\
Total & $29(58.0)$ & $14(28.0)$ & $7(14.0)$ & $50(100)$ \\
Chi-square=6.9112, $P=0.0315^{*}$ & & & \\
\hline
\end{tabular}

(WDSCC: well differentiated squamous cell carcinoma, MDSCC: moderately differentiated squamous cell carcinoma, PDSCC: poorly differentiated squamous cell carcinoma)

$* P<0.05$.

Values are presented as number $(\%)$.

Harshada C. Bhatlawande et al: Role of immunoreactive patterns of lymph nodes in neck dissection cases of oral squamous cell carcinoma: a clinical and histopathological study. J Korean Assoc Oral Maxillofac Surg 2019

Table 3. Comparison of tumor grades to invasive front

\begin{tabular}{lcccc}
\hline Invasive front & WDSCC & MDSCC & PDSCC & Total \\
\hline Individual cells & $0(0.0)$ & $0(0.0)$ & $7(100)$ & $7(14.0)$ \\
Large islands & $17(94.4)$ & $1(5.6)$ & $0(0.0)$ & $18(36.0)$ \\
Nests & $2(50.0)$ & $2(50.0)$ & $0(0.0)$ & $4(8.0)$ \\
Small islands & $10(47.6)$ & $11(52.4)$ & $0(0.0)$ & $21(42.0)$ \\
Total & $29(58.0)$ & $14(28.0)$ & $7(14.0)$ & $50(100)$ \\
Chi-square=61.9642, $P=0.0001 *$ & & &
\end{tabular}

(WDSCC: well differentiated squamous cell carcinoma, MDSCC: moderately differentiated squamous cell carcinoma, PDSCC: poorly differentiated squamous cell carcinoma)

$* P<0.05$.

Values are presented as number $(\%)$.

Harshada C. Bhatlawande et al: Role of immunoreactive patterns of lymph nodes in neck dissection cases of oral squamous cell carcinoma: a clinical and histopathological study. J Korean Assoc Oral Maxillofac Surg 2019 
LN reactivity patterns were assessed according to Tsakraklides rule $\mathrm{e}^{5}$ into lymphocyte predominance, lymphocyte depletion, germinal center predominance, unstimulated node pattern, sinus histiocytosis, cortical hyperplasia, paracortical hyperplasia, increased vascularity, and nodal status of LN.

Clinical parameters in OSCC cases were assessed and compared with histologic parameters and LN reactivity patterns using chi-square analysis as the test of significance.

\section{Results}

Among studied cases, the age range was 30 to 76 years. Within these age groups, $58.0 \%$ of OSCC cases were WDSCC. The male to female ratio was $4: 1$ in our study.(Tables 1 , 2)

There was statistical significance observed between tumor grade and pattern of invasive front $(P=0.0001)$. (Table 3$)$ Of 50 cases, 20 cases showed neural invasion of tumor cells and 10 cases showed vascular invasion of tumor cells. However, there was no statistical significance observed between tumor grade and neural invasion. Among 10 cases that showed vascular invasion, $40 \%$ were WDSCC and PDSCC, while only $20 \%$ were MDSCC $(P<0.05)$. (Tables 4,5$)$

A total of 1,078 LNs were harvested and evaluated from 50 neck dissection cases of OSCC. LNs patterns were observed in the following order: increased vascularity in $472 \mathrm{LNs}$, lymphocyte predominance (LP) pattern in 396 LNs, germinal center predominance (GCP) pattern in $375 \mathrm{LNs}$, unstimulated node pattern (UNP) in $318 \mathrm{LNs}$, cortical hyperplasia $(\mathrm{CH})$ in 299 LNs, paracortical hyperplasia (PCH) in 255 LNs, sinus histiocytosis $(\mathrm{SH})$ pattern in $121 \mathrm{LNs}$, metastases in $56 \mathrm{LNs}$, and lymphocyte depletion (LD) pattern in 18 LNs.(Fig. 1)

Further comparison of metastasis in each level (level I to IV) showed the most metastasis in level II LNs, which was followed by level I, level III, and level IV, in order. Interestingly, $80 \%$ of PDSCC cases with metastasis was in level 1 LNs.(Table 6)

Of 396 LNs with LP pattern, 63.9\% LP pattern LNs were in cases of WDSCC, $22.7 \%$ LP pattern LNs were in cases of MDSCC, and $13.4 \%$ pattern LNs were in cases of PDSCC. This difference between LN LP pattern and tumor grade was statistically significant $(P=0.0005)$. In investigation of LD pattern, $83.3 \%$ of LNs in WDSCC cases showed LD pattern, $11.1 \%$ of LNs in MDSCC cases showed LD pattern, and 1 LN in PDSCC showed LD pattern. This difference was statistically significant $(P=0.0490)$.(Table 7)

For LNs showing SH pattern (121 LNs), 46.3\% were seen in WDSCC, $36.4 \%$ were seen in MDSCC, and $17.4 \%$ were seen in PDSCC. There was statistical significance $(P=0.0500)$ found between tumor grade and SH pattern in LNs.(Table 7)

Of 255 LNs showing PCH pattern, $72.2 \%$ were in WDSCC cases, $14.1 \%$ were in MDSCC cases, and $13.7 \%$ were in PD-

Table 4. Comparison of tumor grades with neural invasion

\begin{tabular}{ccccc}
\hline Neural invasion & WDSCC & MDSCC & PDSCC & Total \\
\hline No & $18(60.0)$ & $10(33.3)$ & $2(6.7)$ & $30(60.0)$ \\
Yes & $11(55.0)$ & $4(20.0)$ & $5(25.0)$ & $20(40.0)$ \\
Total & $29(58.0)$ & $14(28.0)$ & $7(14.0)$ & $50(100)$ \\
Chi-square=3.6952, $P=0.1576$ & & & \\
\hline
\end{tabular}

(WDSCC: well differentiated squamous cell carcinoma, MDSCC: moderately differentiated squamous cell carcinoma, PDSCC: poorly differentiated squamous cell carcinoma)

Values are presented as number $(\%)$.

Harshada C. Bhatlawande et al: Role of immunoreactive patterns of lymph nodes in neck dissection cases of oral squamous cell carcinoma: a clinical and histopathological study. J Korean Assoc Oral Maxillofac Surg 2019

Table 5. Correlation of tumor grades with vascular invasion

\begin{tabular}{|c|c|c|c|c|}
\hline Vascular invasion & WDSCC & MDSCC & PDSCC & Total \\
\hline No & $25(62.5)$ & $12(30.0)$ & $3(7.5)$ & $40(80.0)$ \\
\hline Yes & $4(40.0)$ & $2(20.0)$ & $4(40.0)$ & $10(20.0)$ \\
\hline Total & $29(58.0)$ & $14(28.0)$ & $7(14.0)$ & $50(100)$ \\
\hline
\end{tabular}

(WDSCC: well differentiated squamous cell carcinoma, MDSCC: moderately differentiated squamous cell carcinoma, PDSCC: poorly differentiated squamous cell carcinoma)

$* P<0.05$.

Values are presented as number $(\%)$.

Harshada C. Bhatlawande et al: Role of immunoreactive patterns of lymph nodes in neck dissection cases of oral squamous cell carcinoma: a clinical and histopathological study. J Korean Assoc Oral Maxillofac Surg 2019 


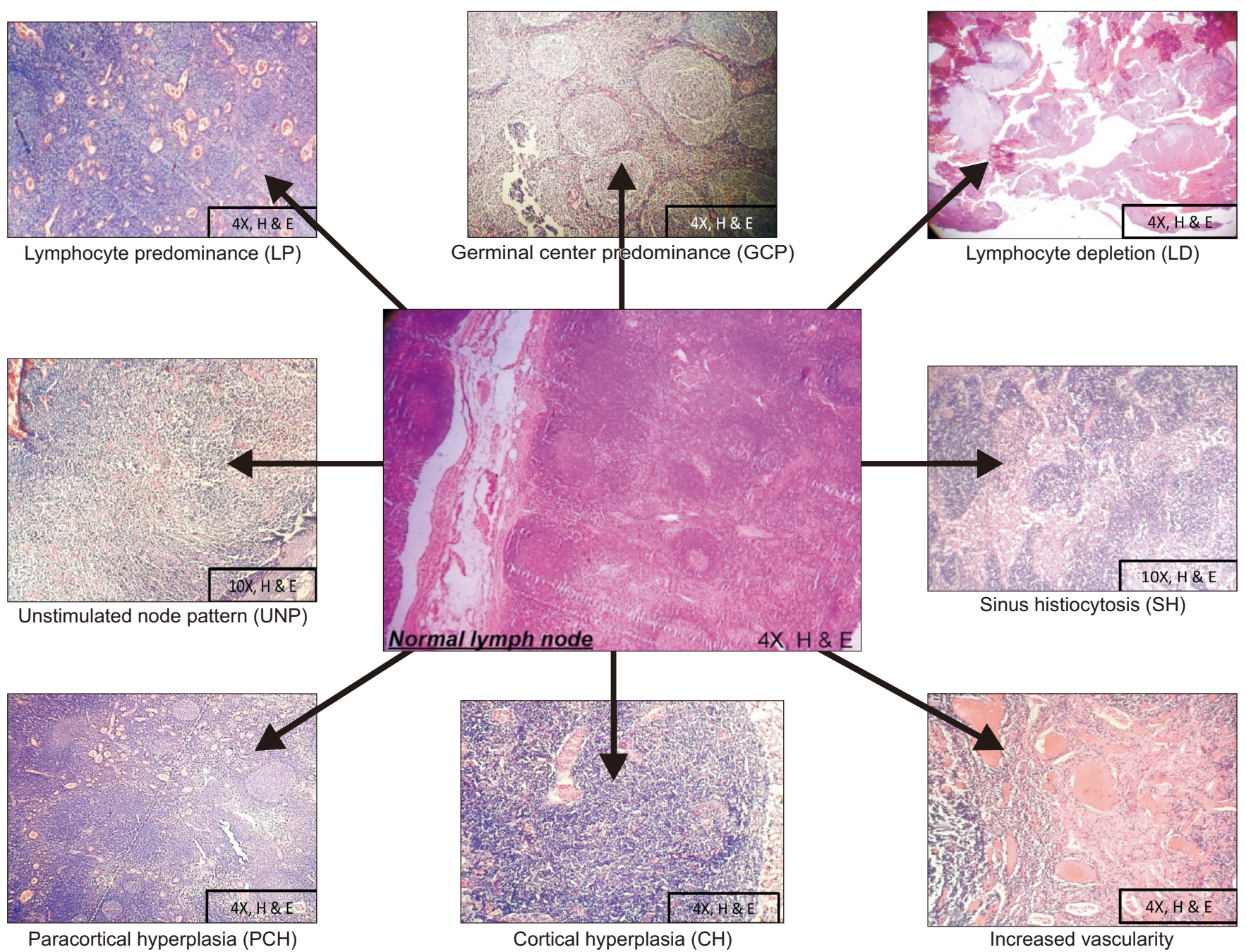

Fig. 1. Reactivity patterns of lymph node.

Harshada C. Bhatlawande et al: Role of immunoreactive patterns of lymph nodes in neck dissection cases of oral squamous cell carcinoma: a clinical and histopathological study. JKorean Assoc Oral Maxillofac Surg 2019

Table 6. Comparison of tumor grades with positive nodes by level

\begin{tabular}{cllll}
\hline Levels of nodes & WDSCC & MDSCC & PDSCC & Total \\
\hline Level I & $0(0.0)$ & $1(20.0)$ & $4(80.0)$ & $5(10.0)$ \\
Level II & $5(62.5)$ & $3(37.5)$ & $0(0.0)$ & $8(16.0)$ \\
Level III & $2(66.7)$ & $0(0.0)$ & $1(33.3)$ & $3(6.0)$ \\
Level IV & $1(100)$ & $0(0.0)$ & $0(0.0)$ & $1(2.0)$ \\
\hline
\end{tabular}

(WDSCC: well differentiated squamous cell carcinoma, MDSCC: moderately differentiated squamous cell carcinoma, PDSCC: poorly differentiated squamous cell carcinoma)

Values are presented as number (\%).

Harshada C. Bhatlawande et al: Role of immunoreactive patterns of lymph nodes in neck dissection cases of oral squamous cell carcinoma: a clinical and histopathological study. JKorean Assoc Oral Maxillofac Surg 2019

SCC cases. The relationship between tumor grade and PCH pattern was statistically significant $(P=0.0001)$. (Table 7)

Of 299 LNs showing $\mathrm{CH}$ pattern, 69.6\% were in WDSCC cases, $17.1 \%$ were in MDSCC cases, and $13.4 \%$ were in PDSCC cases. Tumor grade and pattern of reactivity had a statistically significant relationship $(P=0.00001)$.(Table 7$)$
The GCP pattern was seen in $375 \mathrm{LNs}$, and the UNP was observed in 318 LNs. These patterns showed no significant association with different tumor grades.(Table 7)

Of all 1,078 LNs that were assessed, 5\% showed metastasis. Among these LNs (56 nodes), $42.9 \%$ were in PDSCC cases, $35.7 \%$ were in WDSCC cases, and $21.4 \%$ were in 
Table 7. Comparison of tumor grades in OSCC and lymph node reactivity patterns $(n=1,078)$

\begin{tabular}{|c|c|c|c|c|c|c|}
\hline Reactivity pattern & WDSCC & MDSCC & PDSCC & Total & Chi-square & $P$-value \\
\hline LP & $253(63.9)$ & $90(22.7)$ & $53(13.4)$ & $396(36.7)$ & 15.2691 & $0.0005^{*}$ \\
\hline LD & $15(83.3)$ & $2(11.1)$ & $1(5.6)$ & $18(1.7)$ & 6.0314 & $0.0490 *$ \\
\hline GCP & $223(59.5)$ & $105(28.0)$ & $47(12.5)$ & $375(34.8)$ & 2.9039 & 0.2341 \\
\hline UNP & $169(53.1)$ & $105(33.0)$ & $44(13.8)$ & $318(29.5)$ & 3.6446 & 0.1617 \\
\hline $\mathrm{SH}$ & $56(46.3)$ & $44(36.4)$ & $21(17.4)$ & $121(11.2)$ & 5.7456 & $0.0500^{*}$ \\
\hline $\mathrm{PCH}$ & $184(72.2)$ & $36(14.1)$ & $35(13.7)$ & $255(23.7)$ & 40.2627 & $0.0001^{*}$ \\
\hline $\mathrm{CH}$ & $208(69.6)$ & $51(17.1)$ & $40(13.4)$ & $299(27.7)$ & 33.3713 & $0.0001 *$ \\
\hline Nodal status & $20(35.7)$ & $12(21.4)$ & $24(42.9)$ & $56(5.2)$ & 37.6839 & $0.0001 *$ \\
\hline Increased vascularity & $278(58.9)$ & $141(29.9)$ & $53(11.2)$ & $472(43.8)$ & 7.9112 & $0.0190 *$ \\
\hline
\end{tabular}

(WDSCC: well differentiated squamous cell carcinoma, MDSCC: moderately differentiated squamous cell carcinoma, PDSCC: poorly differentiated squamous cell carcinoma, LP: lymphocyte predominance, LD: lymphocyte depletion, GCP: germinal center predominance, UNP: unstimulated node pattern, SH: sinus histiocytosis, PCH: paracortical hyperplasia, $\mathrm{CH}$ : cortical hyperplasia)

$* P<0.05$.

Values are presented as number (\%).

Harshada C. Bhatlawande et al: Role of immunoreactive patterns of lymph nodes in neck dissection cases of oral squamous cell carcinoma: a clinical and histopathological study. J Korean Assoc Oral Maxillofac Surg 2019

Table 8. Observation of reactivity patterns in cases of oral squamous cell carcinoma with metastatic nodes

\begin{tabular}{lrrrrrrrrr}
\hline \multicolumn{1}{c}{ Grade } & LP & LD & GCP & UNP & SH & PCH & CH & Nodal metastasis & Increased vascularity \\
\hline WDSCC $(\mathrm{n}=8)$ & 59 & 13 & 42 & 21 & 12 & 54 & 39 & 20 & 75 \\
MDSCC $(\mathrm{n}=4)$ & 31 & 1 & 28 & 34 & 13 & 13 & 12 & 12 & 48 \\
PDSCC $(\mathrm{n}=5)$ & 65 & 1 & 51 & 42 & 42 & 32 & 50 & 24 & 86 \\
Total & 155 & 15 & 121 & 97 & 67 & 99 & 101 & 56 & 209 \\
\hline
\end{tabular}

(WDSCC: well differentiated squamous cell carcinoma, MDSCC: moderately differentiated squamous cell carcinoma, PDSCC: poorly differentiated squamous cell carcinoma, LP: lymphocyte predominance, LD: lymphocyte depletion, GCP: germinal center predominance, UNP: unstimulated node pattern, $\mathrm{SH}$ : sinus histiocytosis, $\mathrm{PCH}$ : paracortical hyperplasia, $\mathrm{CH}$ : cortical hyperplasia)

Values are presented as number only.

Harshada C. Bhatlawande et al: Role of immunoreactive patterns of lymph nodes in neck dissection cases of oral squamous cell carcinoma: a clinical and histopathological study. J Korean Assoc Oral Maxillofac Surg 2019

MDSCC cases. This difference was statistically significant $(P=0.0001)$. (Table 7)

Of all 1,078 LNs, 472 LNs exhibited increased vascularity. Among these, $58.9 \%$ LNs with increased vascularity were WDSCC cases, 29.9\% were MDSCC cases, and 11.2\% were PDSCC cases. A statistically significant relationship was found between tumor grade and increased vascularity $(P=0.0190)$. (Table 7)

Interestingly, patterns of $\mathrm{SH}, \mathrm{CH}$, and increased vascularity were found in positive and adjacent nodes more than LP and GCP patterns.(Table 8)

\section{Discussion}

OSCC ranks among the ten most common cancers of the human body ${ }^{1}$. Despite advances in treatment modalities, the survival rate of OSCC remains poor. This could be attributed to locoregional recurrence that occurs secondary to metasta$\operatorname{sis}^{1}$. Because there is an increasing incidence of LN metastasis in the head and neck region, a definite system based on the immune-morphogenic features of LNs is needed to predict prognosis and treatment outcomes ${ }^{6}$.
In the present study, $80 \%$ of OSCC cases were in male patients. This is in accordance with studies showing that the higher incidence of tobacco intake among males is a key causative agent ${ }^{3,6,7}$.

Regarding the pattern of the invasive front of tumor cells, large islands were found in $94.4 \%$ of WDSCC cases, whereas $52.4 \%$ of MDSCC cases showed small islands, and all cases of PDSCC showed individual cells. There was a statistically significant relationship between tumor grade and invasive front $(P=0.0001)$. As tumor grade increases, tumor cells invade in more undifferentiated patterns as per Broder's classification $^{6,8-11}$.

Studies suggest that lymph vessels and veins are associated with a greater incidence of locoregional LN metastasis in oral cancer, making them important prognostic markers. In the present study, $40 \%$ of both WDSCC and PDSCC cases had vascular invasion. This is in contrast to the findings of Anneroth et al. ${ }^{6}$, wherein an increased number of cases exhibited invasion with increased grade from WDSCC to PDSCC ${ }^{6,8-11}$. This inconsistent finding is probably due to the borderline invasion in some cases of early stage OSCC $^{6}$.

In this study, $71.4 \%$ of PDSCC cases were positive for me- 

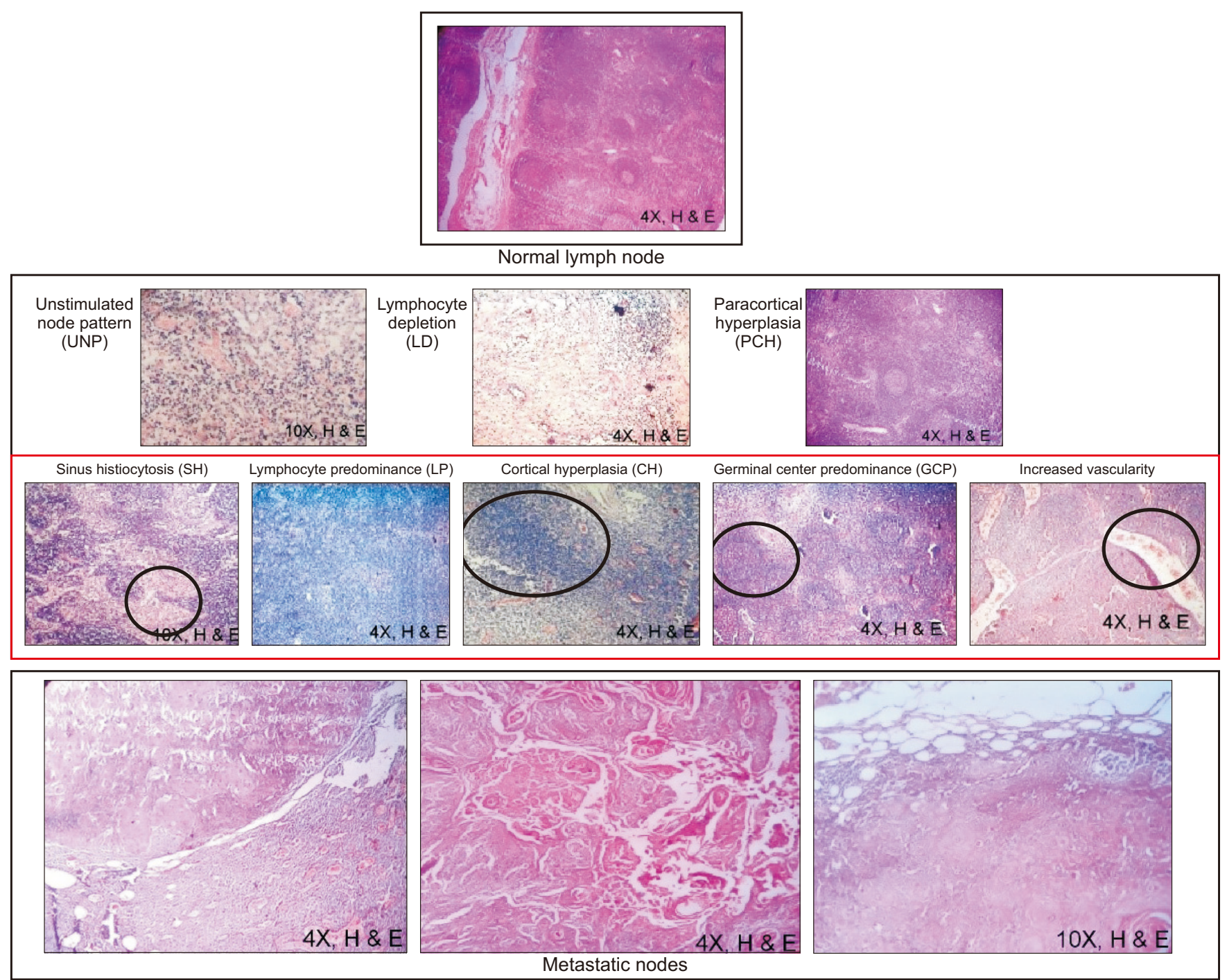

Fig. 2. H\&E stained microscopy images (4x or $10 x)$ of reactive patterns most commonly seen in metastatic and adjacent immunoreactive nodes. Selected regions in the pattern (black circles) show greater metastatic potential due to the respective cell predominance.

Harshada C. Bhatlawande et al: Role of immunoreactive patterns of lymph nodes in neck dissection cases of oral squamous cell carcinoma: a clinical and histopathological study. $J$ Korean Assoc Oral Maxillofac Surg 2019

tastasis. Cells of PD carcinomas lose their cellular adhesion and can migrate further through blood and lymphatics, exhibiting aggressive biological behavior. Metastasis of individual cells is difficult to diagnose by routine histopathology. Studies suggest that LN involvement is an important prognostic factor, and the five-year survival rate is poor in cases with $\mathrm{LN}$ involvement ${ }^{12,13}$.

Saldanha ${ }^{13}$ indicated that in the presence of strong cellular immunity, the germinal center is nonreactive with a thick paracortex and LN invasion does not occur. According to Tsakraklides et al. ${ }^{14}$, LN histology correlated with grade of primary tumor and survival rate in uterine cancer. They found that WDSCC showed a LP pattern and increased survival rate $^{14-20}$.
Of the 608 nodes harvested from WDSCC cases in the present study, $41.6 \%$ LNs showed a LP pattern in which there is an increase in the number of lymphocytes in the paracortex ( $\mathrm{T}$ cell zone). A LD pattern was noted in only $1.7 \%$ of cases, and most were WD carcinomas. LP usually indicates immune exhaustion, and interference with the cytotoxic activity of $\mathrm{T}$ lymphocytes and histiocytes deters their action on metastatic tumor cells to favor metastases. This important observation may aid in understanding vascular invasion, recurrence, and poor survival in some cases of WDSCC.

Tumor invasion and lack of antigen presentation or immune response are also associated with $\mathrm{SH}$. Sinus histiocytes accumulate when there is a need to remove bacteria, debris, or invaded tumor cells during invasion or presentation of an- 
tigenic stimuli ${ }^{5}$. In this study, more LNs showed SH in poorly differentiated carcinoma than in well and moderately differentiated carcinoma. Research has indicated that LNs with $\mathrm{SH}$ are associated with poor survival ${ }^{14-20}$.

$\mathrm{PCH}$ is also an important reactive pattern exhibited in LNs. Host defense cells stimulated by antigen presentation of follicular dendritic cells proliferate in the paracortical zone. Histologically, this presents as proliferation of lymphocytes in the paracortex with abnormal expansion of the interfollicular zone confined to the capsule. In the present study, $30.3 \%$ of LNs without metastasis had PCH in cases of welldifferentiated carcinoma. Literature has shown a relationship between PCH with vascularity and favorable prognosis due to high immune reaction in non-metastatic nodes ${ }^{18}$.

Another hyperplastic pattern seen in LNs is $\mathrm{CH}$, wherein there is a confluent pattern of $\mathrm{T}$ lymphocyte proliferation in the cortex. CH was seen in $34.2 \%$ of LNs in cases of WD carcinomas without metastatic LNs. This is in accordance with a study by Tsakraklides et al. ${ }^{14}$, showing that $\mathrm{CH}$ is associated with UNP and with absence of LN metastases. $\mathrm{CH}$ is considered a form of good immunologic response.

LN vascularity can show multiple patterns, including normal peripheral, hilar, or mixed vascularity, reactive response, or vascularity associated with malignancy. The amount of vascularity depends on the tumor type and extent. In cases of metastatic nodes, there is mixed or peripheral vascularity along with loss of architecture in hilar vessels ${ }^{21}$. Thus, these changes are an important factor in diagnosing malignancy in a $\mathrm{LN}^{22}$. In WD carcinomas, $45.7 \%$ of LNs had increased vascularity, which could be due to reactive phenomena, especially in LNs without metastasis ${ }^{18}$.

As mentioned earlier, not all regional LNs show the same reaction to antigenic stimuli or tumor cells at a given time. Failure of the immune response to clear tumor cells leads to metastasis in regional LNs. Interestingly, of all 1,078 LNs harvested from 50 cases of neck dissection in this study, only 17 cases with 56 harvested LNs showed metastasis (15.2\%). LNs were evaluated in all four levels according to different grades of carcinomas. In WDSCC and MDSCC, maximum metastasis was observed in level II LNs, while PSCC cases showed metastasis predominantly in level I LNs. A study by Yamamoto et al. ${ }^{23}$ suggested there might be a correlation between aggressive proliferating tumor cells and metastases ${ }^{23,24}$. However, we suspect that the phenomenon of skip metastasis could be responsible for the findings observed in WDSCC and MDSCC cases. OSCC mostly spreads through lymphatic channels, and LNs act as anatomic barriers that prevent spread. Positive nodes arise from involvement by metastatic cells. The process of metastasis begins with certain molecular changes that cause a LN to be invaded by tumor cells. For this reason, $\mathrm{LN}$ status is an important predictor of prognosis. Immune reactions occur by complex interactions between tumor-associated antigens and lymphoid cells that result in pattern formation. Few studies have described the relationship of reactive LNs and tumor prognosis ${ }^{13,25}$. The morphologic changes of LNs seen with anti-tumor immune reactivity provide an important tool for study. Recent techniques of sentinel LN biopsies are vital for isolating positive nodes. In this study, the patterns associated with malignant changes indicate the beginning of a new phase of cancer. Reactivity patterns such as $\mathrm{SH}, \mathrm{CH}$, and increased vascularity were found to be associated with LN metastasis.(Fig. 2)

The site and degree of histologic differentiation help to determine tumor cell phenotype and behavior. In the $\mathrm{CH}$ pattern, $\mathrm{T}$ cells predominate in reaction to metastasis due to tumor-associated antigenic stimuli. In the SH pattern, histiocytes predominate at the margins of metastatic cells due to increased immunoblasts in sinuses, which are prone to invasion. In LP and GCP patterns, immune cells predominate and show tumor response as a result of metastasis ${ }^{13}$. With increased vascularity, there is an increased number of feeding vessels at abnormal sites that favor tumor cells instead of the LN.

Other interesting histologic features include the coincidental presence of Warthin's tumor, a tuberculous LN, and extracapsular spread.

The present study demonstrates the importance of analyzing every aspect of LNs. While there may be contradictions and overlapping observations, complete histologic analysis will aid in accurate diagnosis and treatment. In the future, we plan to evaluate LN reactivity patterns immunohistochemically on a larger sample population along with analysis of survival rate.

\section{Conclusion}

LNs present a great source of information in terms of their histologic pattern and clinical presentation. Various head and neck pathologies can present with different histologic immunoreactive patterns in the LN. These patterns do not only depict pathology but also the host's immune response, which can further help to determine treatment and prognostic outcome. The study and inclusion of various LN patterns in routine histopathologic reporting of neck dissection cases may 
help to determine treatment plans and prognosis in OSCC.

\section{ORCID}

Harshada C. Bhatlawande, https://orcid.org/0000-00021509-3209

Alka D. Kale, https://orcid.org/0000-0002-1117-9494

Karishma M. Desai, https://orcid.org/0000-0002-3281$731 X$

Seema Hallikerimath, https://orcid.org/0000-0001-50456856

Chetan Belaldavar, https://orcid.org/0000-0001-9924-3739

Deepa Mane, https://orcid.org/0000-0001-9786-286X

Punnya V. Angadi, https://orcid.org/0000-0001-9263-5027

Manjula M., https://orcid.org/0000-0001-7499-9695

Sidramesh Muttagi, https://orcid.org/0000-0003-2070$047 X$

\section{Authors' Contributions}

H.C.B. participated in data collection. S.M. participated for providing clinical data. H.C.B., A.D.K., and K.M.D. wrote the manuscript. H.C.B., A.D.K., S.H., P.V.A., D.M., C.B., M.M., and K.M.D. participated in study design and analysis. All authors read and approved the final manuscript.

\section{Ethics Approval and Consent to Participate}

The study protocol was approved by the Research and Ethics Committee of KLE VK Institute of Dental Sciences (No. 1079) and the written informed consent was waived.

\section{Conflict of Interest}

No potential conflict of interest relevant to this article was reported.

\section{References}

1. Rivera C. Essentials of oral cancer. Int J Clin Exp Pathol 2015;8:11884-94.

2. Warnakulasuriya S. Global epidemiology of oral and oropharyngeal cancer. Oral Oncol 2009;45:309-16.

3. Bryne M. Prognostic value of various molecular and cellular features in oral squamous cell carcinomas: a review. J Oral Pathol Med 1991;20:413-20.

4. Willard-Mack CL. Normal structure, function, and histology of lymph nodes. Toxicol Pathol 2006;34:409-24.

5. Cottier H, Turk J, Sobin L. A proposal for a standardized system of reporting human lymph node morphology in relation to immunological function. J Clin Pathol 1973;26:317-31.

6. Anneroth G, Batsakis J, Luna M. Review of the literature and a recommended system of malignancy grading in oral squamous cell carcinomas. Scand J Dent Res 1987;95:229-49.

7. Shingaki S, Suzuki I, Nakajima T, Kawasaki T. Evaluation of histopathologic parameters in predicting cervical lymph node metastasis of oral and oropharyngeal carcinomas. Oral Surg Oral Med Oral Pathol 1988;66:683-8.

8. Jakobsson PA, Eneroth CM, Killander D, Moberger G, Mårtensson B. Histologic classification and grading of malignancy in carcinoma of the larynx. Acta Radiol Ther Phys Biol 1973;12:1-8.

9. Bryne M, Koppang HS, Lilleng R, Kjaerheim A. Malignancy grading of the deep invasive margins of oral squamous cell carcinomas has high prognostic value. J Pathol 1992;166:375-81.

10. Klijanienko J, el-Naggar AK, de Braud F, Rodriguez-Peralto JL, Rodriguez R, Itzhaki M, et al. Tumor vascularization, mitotic index, histopathologic grade, and DNA ploidy in the assessment of 114 head and neck squamous cell carcinomas. Cancer 1995;75:164956.

11. Odell EW, Jani P, Sherriff M, Ahluwalia SM, Hibbert J, Levison DA, et al. The prognostic value of individual histologic grading parameters in small lingual squamous cell carcinomas. The importance of the pattern of invasion. Cancer 1994;74:789-94.

12. Akhter M, Hossain S, Rahman QB, Molla MR. A study on histological grading of oral squamous cell carcinoma and its corelationship with regional metastasis. J Oral Maxillofac Pathol 2011;15:168-76.

13. Saldanha P. Morphological assessment of lymph nodes draining carcinoma. MGM J Med Sci 2016;3:190-7.

14. Tsakraklides V, Anastassiades OT, Kersey JH. Prognostic significance of regional lymph node histology in uterine cervical cancer. Cancer 1973;31:860-8.

15. Schnitzer B. Reactive lymphoid hyperplasia. In: Jaffe ES, ed. Surgical pathology of the lymph nodes and related organs. 2nd ed. Philadelphia: W.B. Saunders; 1995:98-132.

16. Stankiewicz C. Prognostic significance of lymph node reactivity in patients with laryngeal carcinoma. Eur Arch Otorhinolaryngol 1994;251:418-22.

17. Malicka K. The assessment of defense function of lymph nodes on the basis of microscopical and clinical studies in laryngeal carcinoma. BTN Pr Wydz Nauk Przyr A 1970;14:5-29.

18. Bennett SH, Futrell JW, Roth JA, Hoye RC, Ketcham AS. Prognostic significance of histologic host response in cancer of the larynx or hypopharynx. Cancer 1971;28:1255-65.

19. Silverberg SG, Chitale AR, Hind AD, Frazier AB, Levitt SH. Sinus histiocytosis and mammary carcinoma. Study of 366 radical mastectomies and an historical review. Cancer 1970;26:1177-85.

20. Kaufmann M, Wirth K, Scheurer J, Zimmermann A, Luscieti P, Stjernswärd J. Immunomorphological lymph node changes in patients with operable bronchogenic squamous cell carcinoma. Cancer 1977;39:2371-7.

21. Bialek EJ, Jakubowski W, Szczepanik AB, Maryniak RK, Prochorec-Sobieszek M, Bilski R, et al. Vascular patterns in superficial lymphomatous lymph nodes: a detailed sonographic analysis. J Ultrasound 2007;10:128-34.

22. Ahuja AT, Ying M, Ho SS, Metreweli C. Distribution of intranodal vessels in differentiating benign from metastatic neck nodes. Clin Radiol 2001;56:197-201.

23. Yamamoto E, Miyakawa A, Kohama G. Mode of invasion and lymph node metastasis in squamous cell carcinoma of the oral cavity. Head Neck Surg 1984;6:938-47.

24. Anderson AO, Anderson ND. Studies on the structure and permeability of the microvasculature in normal rat lymph nodes. Am J Pathol 1975;80:387-418.

25. Ioachim HL, Medeiros LJ. Reactive lymphoid hyperplasia. In: Ioachim HL, Medeiros LJ, eds. Ioachim's lymph node pathology. 4th 
ed. Philadelphia: Wolters Kluwer/Lippincott Williams \& Wilkins; 2009:171-80
How to cite this article: Bhatlawande $\mathrm{HC}$, Kale AD, Desai KM,

Hallikerimath S, Belaldavar C, Mane D, et al. Role of immunoreactive patterns of lymph nodes in neck dissection cases of oral squamous cell carcinoma: a clinical and histopathological study. J Korean Assoc Oral Maxillofac Surg 2019;45:267-275. https://doi. org/10.5125/jkaoms.2019.45.5.267 